\title{
Avocado Fruit Skin Fluorescence following Hot Water Treatments and Pretreatments
}

\author{
Allan B. Woolf and William A. Laing \\ The Horticulture and Food Research Institute of New Zealand, Mt Albert Research Centre, Private Bag \\ 92169, Auckland, New Zealand
}

Additional index words. fruit ripening, Per-sea americana, photosynthesis, heat treatments, postharvest physiology, shelf life, fruit quality

\begin{abstract}
Longitudinal halves of freshly harvested avocado fruit (Persea americana Mill. 'Hass') were pretreated at 38C for 1 hour in a water bath, while the other half remained at $20 \mathrm{C}$ in air. Then the entire fruit was either treated from 1 to 10 minute at 50C, or held at 20C (controls). Fruit quality (daily evaluation of browning and internal quality when ripe), and pulse amplitude modulated (PAM) fluorescence measurements, were made on the skin of each fruit half 1 hour after hot water treatment (HWT), 3 hours later, and each subsequent day until ripening. The pretreated half of the fruit showed almost no development of external browning during the ripening period, while the nonpretreated halves were severely damaged by HWTs. External browning increased with longer HWT duration. Heat damage was also evident as hardening of the skin when fruit ripened, and such damage was reduced by pretreatment and increased with longer HWT duration. HWT had a rapid and marked effect on chlorophyll fluorescence $\left(\mathrm{F}_{\mathrm{v}} / \mathrm{F}_{\mathrm{M}}\right.$ ratio) of avocado skin. Whereas fluorescence of control fruit remained constant over the first 5 days, in both pretreated and nonpretreated fruit, within 1 hour of HWT, the $F_{\mathrm{v}} / F_{\mathrm{M}}$ ratio had dropped to near minimal levels, with little further change. The value of $F_{\mathrm{v}} / F_{\mathrm{M}} 3$ to 6 hours after the HWT was directly related to the duration of the HWT $(P<0.0001)$. Although pretreatment almost eliminated browning, little effect of pretreatment could be detected in the $\mathrm{F}_{\mathrm{v}} / \mathrm{F}_{\mathrm{M}}$ ratio. There was a strong negative correlation $(r=0.93, P<$ 0.0001) between external browning and $F_{v} / F_{M}$ for nonpretreated fruit, but this correlation was not significant for pretreated fruit. We conclude that chlorophyll fluorescence clearly reflects effects of heat on the photosynthetic systems in avocado fruit, but does not detect the alleviation of heat damage by pretreatments.
\end{abstract}

With the anticipated loss of methyl bromide as a disinfestation fumigant and its deleterious effects on fruit quality, there has been a resurgence in research examining heat treatments as a postharvest disinfestation technique. Response to hot water treatments (HWTs) has been examined in a range of crops including mango (Joyce and Shorter, 1994), peach (Sharp, 1990), and papaya (Paull and Chen, 1990). Avocado fruit are unacceptably damaged by HWTs of 3 to 5 min at 50C (Jessup, 1994; Woolf and Lay-Yee, 1996). Heat damage symptoms in avocado fruit are predominantly in the skin, as tissue browning and hardening when ripe (Woolf and Lay-Yee, 1996). Water pretreatment have been employed to impart tolerance to higher temperatures (thermotolerance) in papaya (Couey and Hayes, 1986) and hot air pretreatments used in other crops. Woolf and Lay-Yee (1996) showed in avocados that pretreatments with water at $38 \mathrm{C}$ for $1 \mathrm{~h}$ before subsequent 50C HWTs almost completely eliminate external browning and reduce incidence of hard skin and a range of internal disorders.

Photosynthesis is very sensitive to heat stress (Havaux, 1993a; Schreiber and Berry, 1977) with the usually irreversible damage postulated to be instigated by increased membrane fluidity at higher temperatures (Berry and Bjorkman, 1980; Schreiber and Berry, 1977). Chlorophyll fluorescence, a sensitive indicator of the state of the photosynthetic apparatus, is often used as a nondestructive probe of heat damage (Schreiber and Berry, 1977). Fluorescence measures how light energy absorbed by the chlorophyll is dispersed. When the chloroplasts are damaged, consistent changes in fluorescence occur. These changes can be interpreted in terms of the underlying physiological mechanism causing them, or

Received for publication 6 May 1995. Accepted for publication 19 Sept. 1995 We acknowledge the excellent technical assistance of Amanda Yeates. We also thank Dennis Greer and John Meekings for the loan of their PAM fluorometers. The cost of publishing this paper was defrayed in part by the payment of page charges. Under postal regulations, this paper therefore must be hereby marked advertisement solely to indicate this fact. simply used as a sensitive indicator of stress. We take the latter approach in the paper.

Fluorescence is used to examine damage to the photosynthetic apparatus of heat damaged leaves and fruit. In leaves, the minimal level of fluorescence in weak light $\left(\mathrm{F}_{\mathrm{o}}\right.$; the fluorescence intensity with all photosystem II reaction centers open, for terminology see van Kooten and Snel, 1990) increases with increasing temperature until complete destruction of photosystem II is thought to occur at temperatures around 45C (Schreiber and Berry, 1977). Associated with this appears to be a drop in FM (the fluorescence intensity with all reaction centres closed, with minimal non photochemical quenching) at higher temperatures (above 38C) (Havaux, 1993a; Janssen and van Hasselt, 1994). From these data the ratio $F_{v} / F_{M}$ is calculated where $F_{v}=F_{M}-F_{0}$. This ratio is a measure of the quantum efficiency of photosystem II. Damage to the photosynthetic apparatus is particularly severe in the dark, while moderate light can provide protection from heat damage (Havaux et al., 1991; Schreiber and Berry, 1977). In fruit, skin fluorescence has been characterized (Gross and Ohad, 1983; Smillie, 1992), and the effect of heat on fluorescence studied (Joyce and Shorter, 1994; Smillie, 1992). HWTs of mango (47C for $25 \mathrm{~min}$ after the core reached $47 \mathrm{C}$ ) resulted in a significant reduction of the $\mathrm{F}_{\mathrm{v}} / \mathrm{F}_{\mathrm{M}}$ ratio, caused by a transient increase in $\mathrm{F}_{\mathrm{o}}$ and decrease in $\mathrm{F}_{\mathrm{v}}\left(\mathrm{Joyce}_{\mathrm{N}}\right.$ and Shorter, 1994). The photosynthetic apparatus is able to acclimate rapidly to heat stress, with $35 \mathrm{C}$ pretreatment for $2 \mathrm{~h}$ increasing thermotolerance by about 5C in potato leaves (Havaux, 1993b) while growth at higher temperatures is also effective in increasing thermotolerance (Schreiber and Berry, 1977).

In this work, we examined the effect of HWTs and $38 \mathrm{C}$ water pretreatment on the chlorophyll fluorescence of avocado skin, relating this to skin damage induced by HWTs. We found that while chlorophyll fluorescence is a sensitive indicator of heat stress to the skin in a manner directly proportional to the HWT duration, fluorescence changes are not a satisfactory indicator of the extent of damage to the skin of avocado. 


\section{Material and Methods}

Fruit. Avocado fruit (Persea americana Mill. 'Hass') weighing 210 to $240 \mathrm{~g}$ were picked from a commercial orchard on 27 Nov. and 12 Dec. 1994. All treatments and storage were carried out in a controlled environment room $(20 \mathrm{C}, 60 \% \mathrm{RH})$ blacked out to reduce light levels to $<1 \mu \mathrm{mol} \cdot \mathrm{m}^{-2} \cdot \mathrm{s}^{-1}$ as measured (Li-Cor; Lincoln, Neb.) Fruit were stored during the experiment in enclosed fruit trays covered with dark towels to minimize light exposure.

Hot water treatments and pretreatments. Pretreatments at 38C and 50C HWTs were carried out in large water baths as described by Woolf and Lay-Yee (1996) with water temperature varying by no more than $0.2 \mathrm{C}$ from the set temperature. To minimize the effects of inter-fruit variability, half of each fruit was pretreated at $38 \mathrm{C}$ for $1 \mathrm{~h}$ by laying fruit sideways on plastic mesh so that one longitudinal half of each fruit was submerged in $38 \mathrm{C}$ water, while the other half was exposed to air at 20C. The halftime for heating skin tissue (at $0.5 \mathrm{~cm}$ depth) was less than 1 rein, and skin on the top (air at 20C) half of the fruit did not increase by more than $5 \mathrm{C}$ over the pretreatment period. Immediately after this pretreatment, fruit were completely immersed in 50C HWTs for 1, 3, 5, or 10 rein, and left at $20 \mathrm{C}$ in the dark to ripen. Control fruit were left at $20 \mathrm{C}$ after pretreatment. The fruit were exposed to fluorescent room lights for about 10 min each day during quality assessment after chlorophyll fluorescence measurements were made.

Fruit quality evaluation. External browning was rated daily on a relative scale of 0 to $3(0=$ no occurrence; $0.5=$ browning of $<$ $10 \% ; 1.0=10 \%$ to $20 \% ; 1.5=20 \%$ to $30 \% ; 2=50 \%$ to $75 \% ; 2.5$ $=75 \%$ to $90 \% ; 3.0=>90 \%$ of the fruit surface). Evaluation of fruit quality was carried out as each fruit reached a "ripe to eat" stage was determined by gentle hand-squeezing fruit daily, and the number of days to reach ripeness recorded (shelf life). A range of fruit quality factors were measured, including hard skin (hardening of the skin determined when cutting fruit with a knife), rated on a scale of 0 to 3 where $0=$ no occurrence; $1=$ slight; $2=$ a level at which the consumer would notice, and possibly reject the fruit; 3 $=$ severe. Other factors such as the incidence of rots and internal browning (described by Hopkirk et al., 1994) were examined but data are not presented.

Fluorescence measurements. Fluorescence of dark-adapted fruit was measured using a fluorometer (Schreiber et al., 1986) (PAM 101 and 103; H. Waltz, Effeltrich, Germany). After the completion of the HWT, fluorescence was measured at $20 \mathrm{C}$ at $1 \mathrm{~h}$ (after the fruit had cooled), and 3 to $6 \mathrm{~h}$ later, and daily thereafter. Fluorescence was measured at the same three marked locations on each half of the fruit. The minimum fluorescence $\left(\mathrm{F}_{\mathrm{o}}\right)$ was measured using a low modulated measuring light with excitation at 655 $\mathrm{nm}$ from a light emitting diode (LED), and maximum fluorescence $\left(\mathrm{F}_{\mathrm{M}}\right)$ was measured with a $1 \mathrm{sec}$ pulse of excitation light of 4800 $\mu \mathrm{mol} \cdot \mathrm{m}^{-2} \cdot \mathrm{s}^{-1}$ from a halogen lamp. This light intensity gave maximum $\mathrm{F}_{\mathrm{M}}$ for avocados.

Chlorophyll measurement. Avocado skin tissue was sampled by removing 10 disks with a cork borer $(1.35 \mathrm{~cm}$ in diameter) around the equator of each fruit. In unripe fruit, skin disks were obtained by excising the skin immediately above the flesh/skin interface with a scalpel. In ripe fruit, the skin was peeled before the disks were taken. The-disks were frozen in liquid $\mathrm{N}$ and stored at $-20 \mathrm{C}$ until extraction. The disks were ground in liquid $\mathrm{N}, 1$ to $2 \mathrm{~g}$ of powder was added to $10 \mathrm{ml}$ of $85 \%$ acetone containing $1 \% \mathrm{w} / \mathrm{v} \mathrm{CaCO}_{3}$, and the sample homogenized with a Polytron (30 sec at maximum speed; Thayer and Bjorkman, 1990). The extract was centrifuged $(3000 \times \mathrm{g})$ and optical densities measured at 663, 652, and $645 \mathrm{~nm}$. Chlorophyll was calculated using standard formulae (Arnon, 1949).
Experimental design and statistics. The main fluorescence experiment was carried out twice. Within each experimental replicate, six fruit were treated at each HWT duration, in a randomized design. Data manipulation and analysis was carried out using SAS (SAS Inst., 1989). The two experiments gave very similar results and the data were therefore combined for presentation ( $\mathrm{n}=12$ fruit).

\section{Results}

Fruit quality. The efficacy of the pretreatment is clearly apparent in Fig. 1 showing that the right hand portion of the fruit (pretreated at 38C for $1 \mathrm{~h}$ ) remains green and therefore lighter, while the left half (at $20 \mathrm{C}$ for $1 \mathrm{~h}$ ) is brown due to the heat damage caused by the subsequent HWT of 50C for 3 min. The external damage rating reflects heat damage to the skirt and is clearly distinguishable from the natural purpling/blackening of the avocado skin during ripening. The nonpretreated half of the fruit was severely damaged by HWTs of 3, 5, and $10 \mathrm{~min}$ (Fig. 2A), while the pretreated half of the fruit showed almost no development of external damage during the ripening period (Fig. 2B). In the half of the fruit not pretreated, external damage increased with longer HWT duration. Following HWTs of 3, 5, and 10 rein, external damage increased markedly over the first 3 to 4 days at 20C, and more slowly after this time. External damage after the 10 min HWT initially lagged behind the 3 and 5 min treatments, but reached a higher final level.

In addition to skin browning, the skin of ripe fruit hardened following HWTs (Fig. 3). In nonpretreated fruit, the average severity of hard skin increased with longer HWT duration, reaching a maximum level of almost 2 following a 10 min HWT. However, the pretreated half of the fruit exhibited significantly lower levels of hard skin at all HWT durations (F'< 0.0001), with the average hard skin rating not reaching $>0.6$.

The shelf life (time to ripening) was affected by HWT duration $(P<0.0001)$. Shelf life was reduced from 11 days in fruit with no HWT to 9 days for fruit treated for 5 or $10 \mathrm{~min}$ at $50 \mathrm{C}$ (data not shown).

The effects of HWT and pretreatment on the $\mathrm{F}_{v} / \mathrm{F}_{\mathrm{M}}$ ratio over

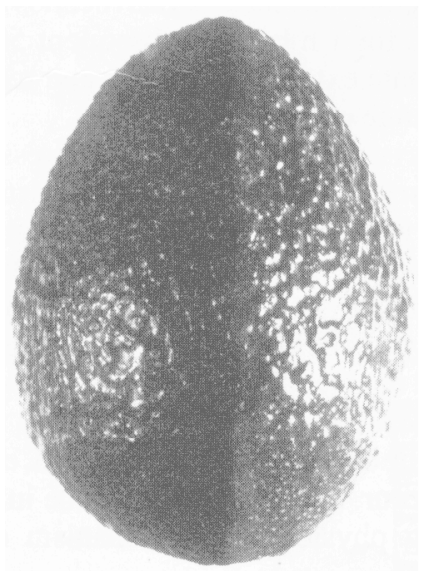

Fig. 1. Effect of pretreating (38C for $1 \mathrm{~h}$ ) the right half of an avocado fruit and subsequently treating the whole fruit at $50 \mathrm{C}$ for $10 \mathrm{~min}$. The nonpretreated left half exhibits severe heat damage (browning), while the right half (pretreated), is green and continues to ripen to a natural purple/black colour. 


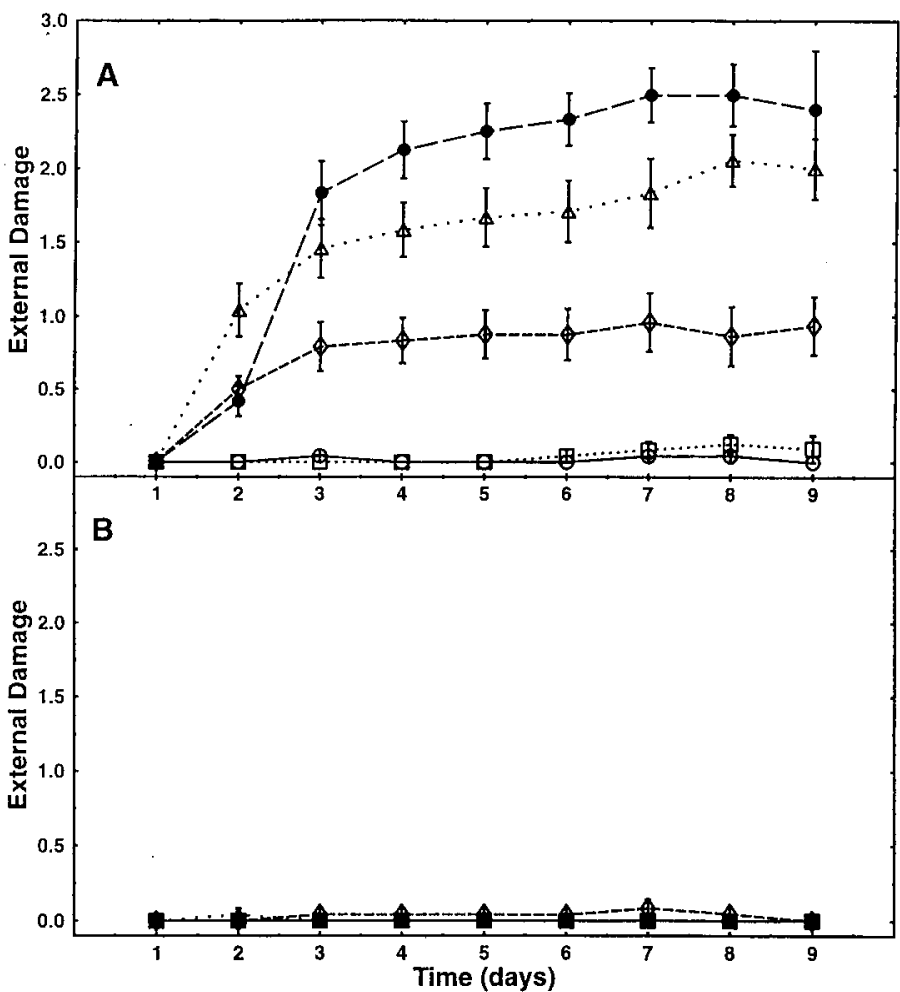

Fig. 2. The effect of pretreatment and HWTs at 50C on the external damage of avocado skins. Half of each fruit was exposed to a $1 \mathrm{~h}$ pretreatment at $38 \mathrm{C}$, then each entire fruit was HWT for $0 \min (\bigcirc) ; 1 \min (\square) ; 3 \min (\diamond) ; 5 \min (A)$; and $10 \min (\bullet)$, without pretreatment $(\mathbf{A})$ or with pretreatment $(\mathbf{B})$. Vertical bars represent $\pm \mathrm{SE}$.

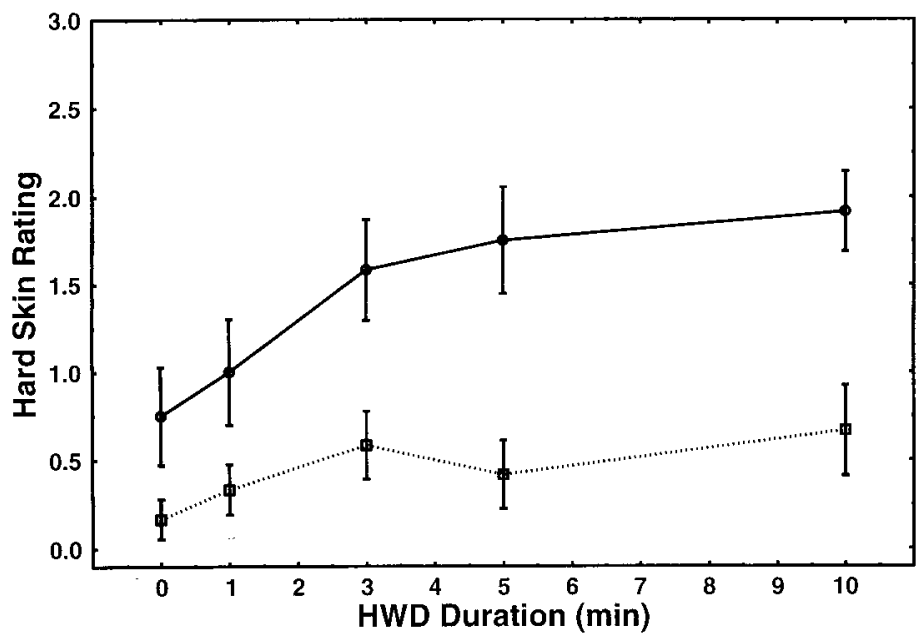

Fig. 3. The effect of HWT at 50C duration on the hard skin rating in avocados either pretreated at $38 \mathrm{C}$ for $\mathrm{Ih}(\square)$ or not pretreated $(\mathrm{O})$. Vertical bars represent \pm SE.

time at $20 \mathrm{C}$ are presented in Fig. 4. The mean $\mathrm{F}_{\mathrm{v}} / \mathrm{F}_{\mathrm{M}}$ ratio before treatment was $0.813( \pm 0.001, \mathrm{n}=360)$, similar to values for healthy leaves (Adams et al., 1990; Bjorkman and Demmig, 1987). For fruit without HWT, the $\mathrm{F}_{V} / \mathrm{F}_{\mathrm{M}}$ ratio remained constant over the first 5 days in both pretreated and nonpretreated fruit halves, then decreased slightly as fruit darkened during ripening to a final level of $0.719( \pm 0.007, n=42)$ after 9 days at 20C. In contrast, HWTs had a rapid and marked effect on skin fluorescence. Within $1 \mathrm{~h}$ after all HWTs, the $\mathrm{F}_{\mathrm{v}} / \mathrm{F}_{\mathrm{M}}$ ratio had dropped to their respective nearminimal levels, and over the following 8 days only small changes in the $\mathrm{F}_{\mathrm{v}} / \mathrm{F}_{\mathrm{M}}$ ratio occurred. The fluorescence time-course for each HWT were similar in both pretreated and non pretreated fruit. The

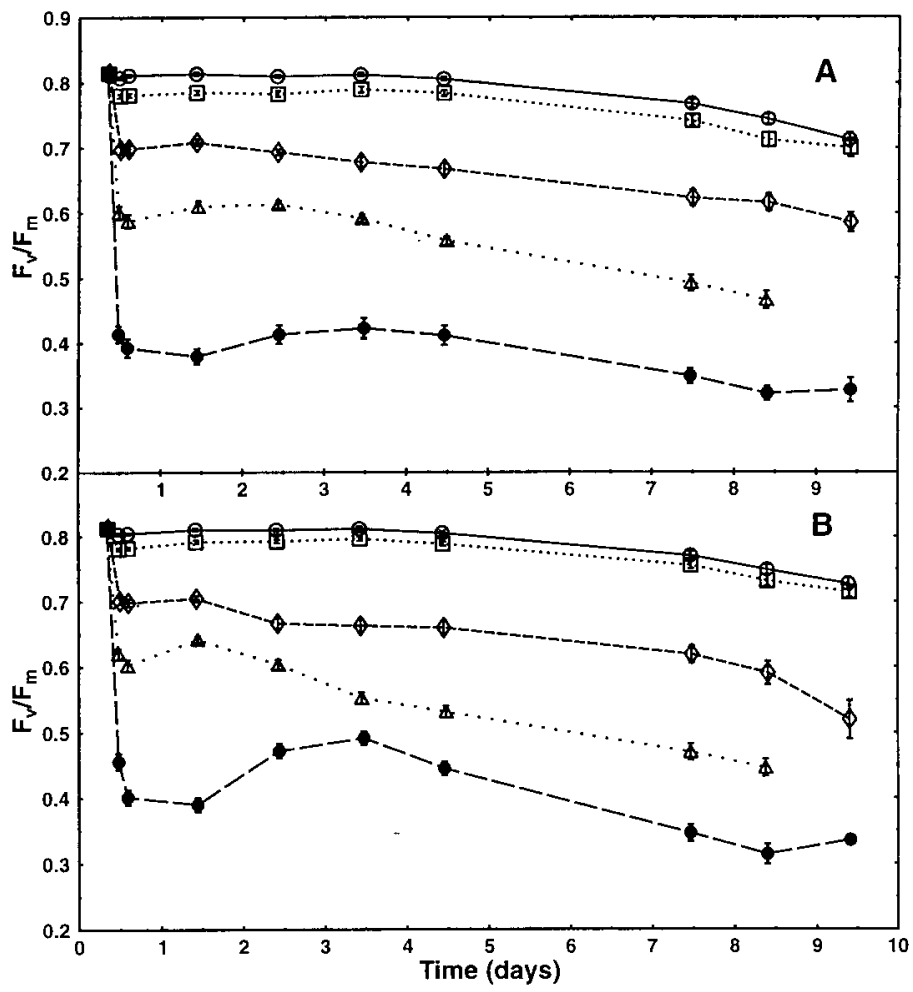

Fig. 4. The effect of pretreatment and HWTs at 50C on the $\mathrm{F}_{\mathrm{v}} / \mathrm{F}_{\mathrm{M}}$ ratio of avocado skins. Half of each fruit was exposed to a $1 \mathrm{~h}$ pretreatment at $38 \mathrm{C}$, then each entire fruit was HWT for $0 \min (\bigcirc) ; 1 \min (\square) 3 \min (0) 5 \min (\Delta)$; and $10 \min (\bullet)$, without pretreatment (A) or with pretreatment $(\mathbf{B})$. Vertical bars represent \pm SE.

only major difference between the pretreated and nonpretreated fruit halves was the kinetics of the 10 rein, and to a lesser extent 5 min HWT, where pretreatment induced a slight recovery of $\mathrm{F}_{\mathrm{v}} / \mathrm{F}_{\mathrm{M}}$ between 2 and 4 days (Fig. 4A cf 3B) However, trends were similar after 7 days.

The $\mathrm{F}_{0}$ time-course after HWT are shown in Fig. 5, using a $\log _{10}$ time scale to improve clarity In the control half of the fruit, $\mathrm{F}_{\mathrm{o}}$ initially declined slightly, then rose again over the last 3 days of measurement (Fig. 5A). For pretreated fruit halves, the $\mathrm{F}_{\mathrm{o}}$ value following HWT was significantly higher $(P<0.01)$ than in the nonpretreated half of the fruit, particularly for longer HWT duration (Fig. 5B). However, at the two longer HWTs (5 and 10 rein), $\mathrm{F}_{\mathrm{o}}$ in nonpretreated fruit halves declined between 3 and 5 days before rising again towards the end of the experiment. $\mathrm{F}_{\mathrm{o}}$ values for pretreated fruit halves did not show this decrease. In fruit halves not hot water treated, $\mathrm{F}_{\mathrm{M}}$ and $\mathrm{F}_{\mathrm{v}}$ declined after the first measurement in both pretreated and non pretreated halves by about $10 \%$, then remained constant to day 5 , after which there was a small decline (data not shown). Because both FM and F, declined similarly, there was no effect on the $\mathrm{F}_{\mathrm{v}} / \mathrm{F}_{\mathrm{M}}$ ratio (Fig. 4).

The $\mathrm{F}_{\mathrm{v}} / \mathrm{F}_{\mathrm{M}}$ ratio measured 3 to $5 \mathrm{~h}$ after $\mathrm{HWT}$, declined linearly with increasing HWT duration (Fig. 6). Data for pretreated and nonpretreated halves of the fruit were not significantly different. The best linear regression fit to the combined pretreated and non pretreated data, had an intercept of $0.818( \pm 0.004)$ and a slope of $-0.0421( \pm 0.0007)(P<0.0001, \mathrm{n}=720)$. Pretreatment as a class factor in a SAS general linear model was nonsignificant.

The relationship between external damage and the $\mathrm{F}_{v} / \mathrm{F}_{\mathrm{M}}$ ratio at day 6 (before ripening) is shown in Fig. 7. There was a strong negative correlation $(r=0.84, P<0.0001)$ between external damage and $\mathrm{F}_{v} / \mathrm{F}_{\mathrm{M}}$ for nonpretreated fruit halves. This correlation was not significant for halves pretreated at $38 \mathrm{C}$ for $1 \mathrm{~h}$. 


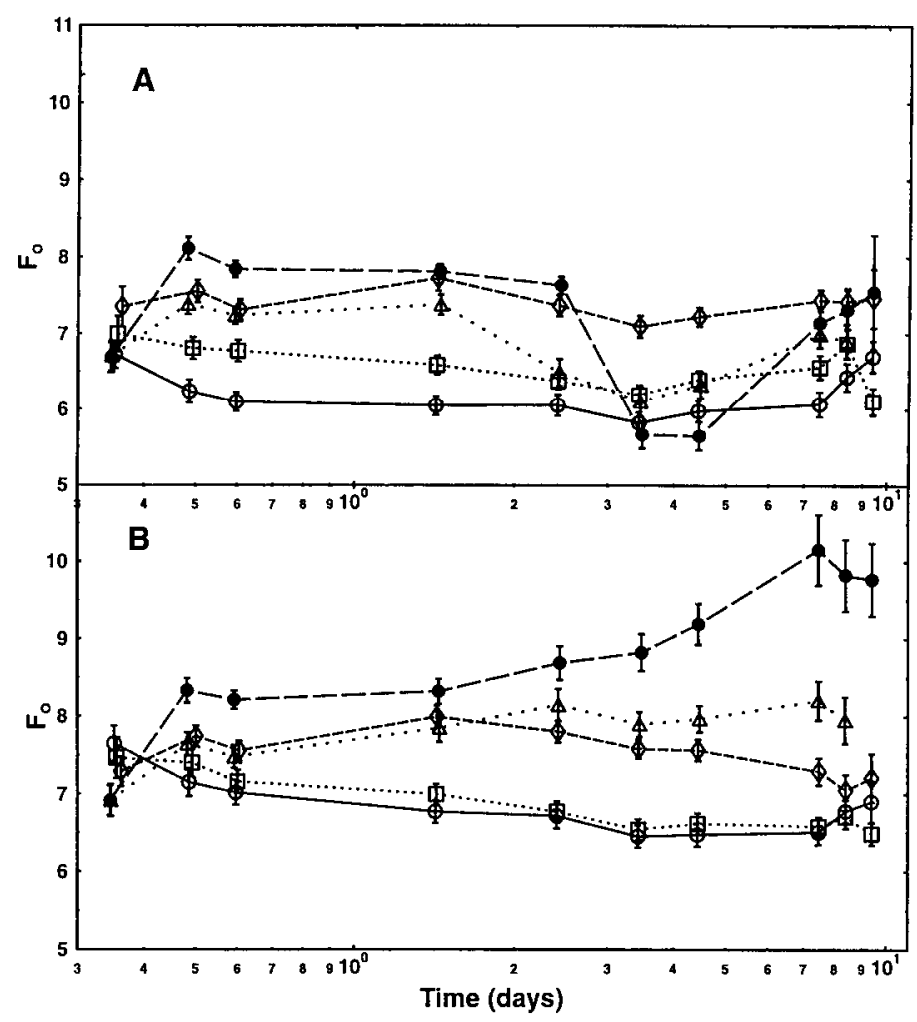

Fig. 5. The effect of pretreatment and HWTs at 50Con the $F_{0}$ value of avocado skins. Half of each fruit was exposed to a $1 \mathrm{~h}$ pretreatment at $38 \mathrm{C}$, then each entire fruit was HWT for $0 \mathrm{~min}(\mathrm{O}) ; 1 \mathrm{~min}(\square) ; 3 \mathrm{~min}(\diamond) ; 5 \min (\Delta)$; and $10 \mathrm{~min}(\bullet)$, without pretreatment $(\mathbf{A})$ or with pretreatment $(\mathbf{B})$. Vertical bars represent \pm SE.

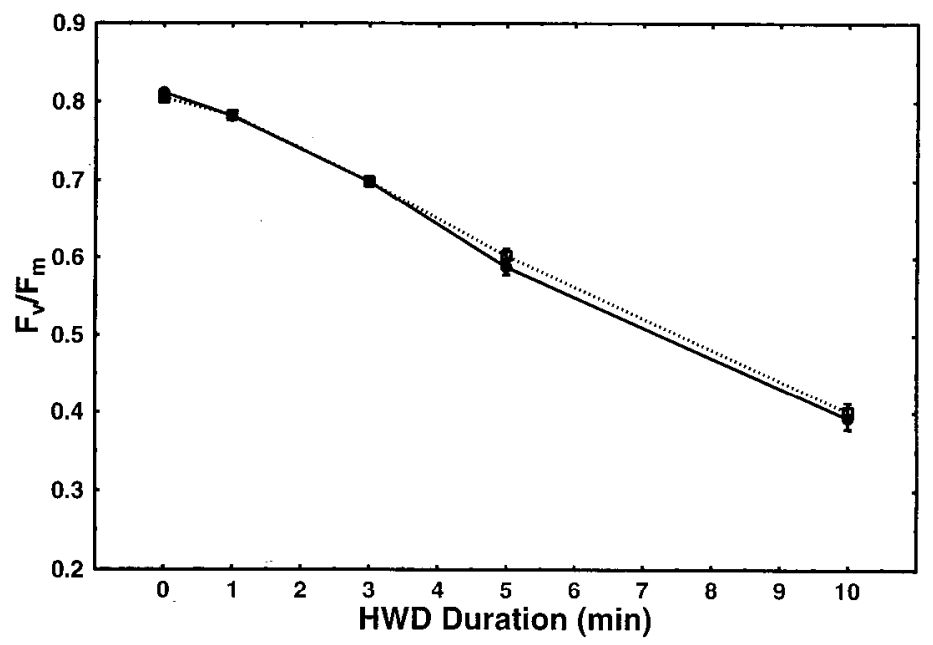

Fig. 6. The effect of HWT at 50C duration on the $\mathrm{F}_{\mathrm{v}} / \mathrm{F}_{\mathrm{M}}$ ratio in avocado skin for avocados either pretreated at 38C for $1 \mathrm{~h}(r=0.96$, slope $=-0.041 \pm 0.001$, intercept $=0.815 \pm 0.005, \mathrm{P}<0.0001, \mathrm{n}=360)$ or not pretreated $(r=0.95$, slope $=-0.042 \pm 0.001$, intercept $=0.817 \pm 0,006, P<0.0001, \mathrm{n}=360)$. Values plotted are means of measurements taken during day 3 following treatment.

Chlorophyll levels in fruit. As the fruit ripened, the skin darkened and masked the unripe green color in the fruit. However, there was no change in the skin chlorophyll during this ripening process (Table 1 ). Chlorophyll content was expressed on a surface area basis to avoid problems of sampling different depths of the skin in hard unripe fruit and soft ripe fruit. In unripe fruit, the 10 min HWT had little effect on chlorophyll content compared to the controls. After the fruit had ripened, there was a significant $(P=0.02)$ reduction in the chlorophyll content of HWT fruit compared to control fruit of $10 \%$ to $16 \%$.

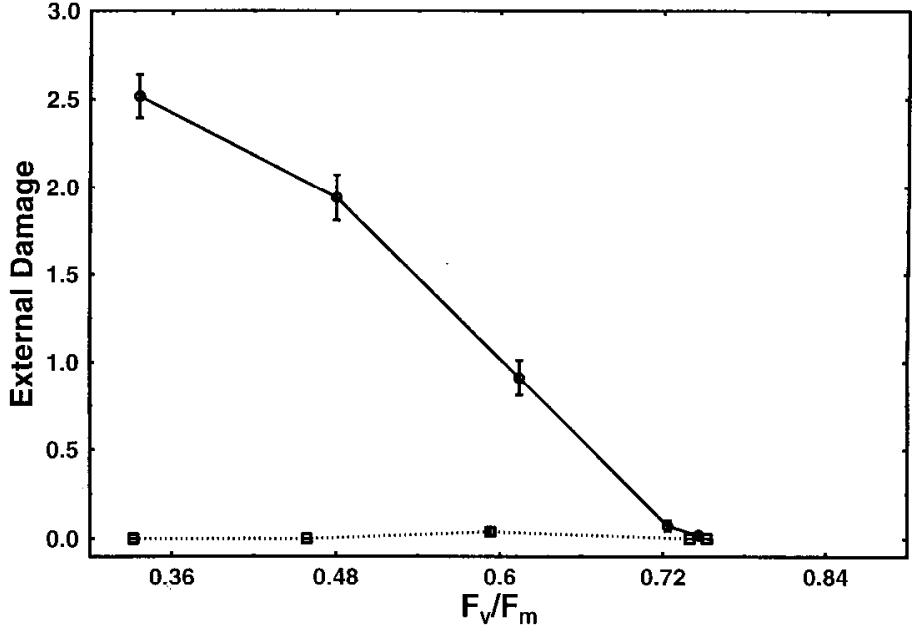

Fig. 7. The relationship between the $\mathrm{F}_{\mathrm{v}} / \mathrm{F}_{\mathrm{M}}$ ratio and external damage of avocado skin, for fruit either pretreated at $38 \mathrm{C}$ for $1 \mathrm{~h}(\mathrm{r}=0.82, P<0.0001, \mathrm{n}=54)$ or not pretreated [ $r=0.01$, (not significant), $\mathrm{n}=54$ ], Vertical bars represent \pm SE.

\section{Discussion}

The increased extent of damage to avocados resulting from longer HWT duration without pretreatment (Fig. 2A) closely parallels the reduction in $\mathrm{F}_{\mathrm{v}} / \mathrm{F}_{\mathrm{M}}$ immediately after $\mathrm{HWT}$, and over time (Fig. 4A). However, the dramatic reduction in heat damage by pretreatments, as determined by browning (Fig. 2B) and skin hardening (Fig. 3), was not mirrored in the pattern of $\mathrm{F}_{\mathrm{v}} / \mathrm{F}_{\mathrm{M}}(\mathrm{Fig}$. 4B). Following 50C HWT of 5 or 10 rein, the greater recovery of $\mathrm{F}_{\mathrm{v}} / \mathrm{F}_{\mathrm{M}}$ in pretreated compared to nonpretreated fruit halves was small, although statistically significant

Fruit quality. The fruit quality responses observed in this work (browning and hardening of the skin) are consistent with previous work where avocados were stored at 6C after the HWT (Woolf and Lay-Yee, 1996). Other internal quality factors, such as tissue breakdown and rots, were relatively unaffected by HWT (data not shown). We suggest that the many deleterious effects of HWTs found in previous work where fruit were stored at low temperatures may have been consequence of the combined stress of heat followed by low temperature storage.

The HWTs were associated with a range of damage symptoms in avocado fruit. The main form of external damage was browning of the skin, which was not markedly different to the natural ripening color of 'Hass' (purple/black). It is possible that the HWTs cause damage to membranes (particularly of chloroplasts) in the skin cells leading to increased 'leakiness' (Lafuente et al., 199 1), which could result in leakage of enzymes involved in browning such as polyphenol oxidase (PPO) (Vamos-Vigyazo, 198 1). The release of such enzymes, normally localized in the chloroplasts, and their reaction with substrates released from leaky vacuoles, would likely result in browning. This damage to cell and organelle membranes occurs during exposure to high tempera-

Table 1. Skin chlorophyll in green, unripe fruit (3 days after harvest), and purple/black, ripe fruit (11-12 days after harvest), as affected by pretreatment (38C for $1 \mathrm{~h}$ ) and HWT (hot water treatment; 50C for 10 rein). The values are the mean and standard error $(n=6)$ expressed as $\mathrm{mg}$ chlorophyll/ $\mathrm{m}^{2}$.

\begin{tabular}{lcccc}
\hline \hline $\begin{array}{l}\text { Stage of fruit } \\
\text { ripening }\end{array}$ & Control & Pretreated & HWT & $\begin{array}{c}\text { Pretreated } \\
+ \text { HWT }\end{array}$ \\
\hline Unripe & $354 \pm 13$ & $342 \pm 5$ & $349 \pm 9$ & $336 \pm 9$ \\
Ripe & $357 \pm 20$ & $375 \pm 21$ & $323 \pm 14$ & $315 \pm 23$ \\
\hline
\end{tabular}


tures, long after the chloroplast photosystem II functioning collapsed. However, the most extreme HWT only resulted in a 10 to $16 \%$ reduction in chlorophyll content, which may suggest that chloroplast breakage was relatively minor.

Fluorescence. The green avocado skin has a normal functioning photosynthetic system as indicated by fluorescence $\left(\mathrm{F}_{\mathrm{v}} / \mathrm{F}_{\mathrm{M}}=0.813\right.$; Smillie, 1992) similar to that found in photosynthetically active leaves (Adams et al., 1990; Bjorkman and Demmig, 1987). Even the ripe purple/black fruit still showed relatively high $\mathrm{F}_{\mathrm{v}} / \mathrm{F}_{\mathrm{M}}$ of 0.719 ), indicating functional chloroplasts. This conclusion is supported by the observation that the chlorophyll content changed little during ripening after the 10 min HWT (Table 1). The small drop in the ratio was caused by the decline in FM and not due to a rise in $\mathrm{F}_{0}$.

Chlorophyll fluorescence is a sensitive indicator of stresses affecting the photosynthetic system. Photoinhibition (high light/cold temperature; Greer et al., 1988) and water stress (Havaux and Lannoye, 1983) significantly change fluorescence of leaves, and the level of stress is reflected in the effect on fluorescence. Fluorescence has also been used to probe the effect of high temperatures on leaf photosynthesis (Havaux, 1993a; Janssen and van Hasselt, 1994; Schreiber and Berry, 1977; van Kooten and Snel, 1990). Heat disrupts the chloroplast membranes and denatures proteins. Thus, temperatures $>45$ to $50 \mathrm{C}$ are usually detrimental to photosynthesis. Our results show that chloroplast fluorescence in avocado skins is a sensitive indicator of heat stress to the photosynthetic apparatus. A 1-min exposure to 50C resulted in a permanent, reproducible reduction of the $F / F_{M}$ ratio by about $10 \%$, and fluorescence responded to increasing heat stress with a proportional drop in the $\mathrm{F}_{\mathrm{v}} / \mathrm{F}_{\mathrm{M}}$ ratio (Fig. 6).

The ability of the leaf photosynthesis system to acclimate to heat stress has been established (Havaux, 1993b; Schreiber and Berry, 1977). In avocados, however, the fluorescence response at $50 \mathrm{C}$ was relatively unaffected by pretreatments that totally protect the skin from visible damage. Any changes due to pretreatment were very subtle changes in the kinetics of both $\mathrm{F}_{\mathrm{v}} / \mathrm{F}_{\mathrm{M}}$ and $\mathrm{F}_{\mathrm{o}}$ (Fig. 4 and 5). This result suggests that 50C HWTs were higher than even a pretreated avocado photosynthesis system can tolerate, in spite of the fact that other cell processes and general membrane integrity appear to very successfully acclimate to a 50C HWT when pretreated at $38 \mathrm{C}$. Consequently, while $\mathrm{F}_{\mathrm{v}} / \mathrm{F}_{\mathrm{M}}$ can provide sensitive information about heat stress to the chloroplast, proportional to the duration of HWT applied to the fruit, it can not discriminate between damaged and acceptable fruit. In contrast, Joyce and Shorter (1994) reported that 47C HWT reduced the $\mathrm{F}_{\mathrm{v}} /$ FM ratio of mango fruit, and a 37C air pretreatment, somewhat ameliorated this reduction. Because the duration of HWT was shorter for the pretreated fruit halves than for the nonpretreated halves, it is difficult to interpret this reduction. particularly because of the lack of clear pretreatment effects on peel injury.

Chlorophyll fluorescence of avocado skin showed little sign of recovery following HWT (Fig. 4), as also found in mangoes (Joyce and Shorter, 1994). Whereas recovery of photosynthesis and fluorescence after a variety of stresses is normal in leaves (Greer and Laing, 1988), usually there is little recovery after heat damage (Havaux, 1993b). This probably reflects the damage to the electron donating/ water splitting side of photosystem II rather than to the more easily repairable acceptor side occurring in other stresses (Havaux, 1993a).

While chlorophyll fluorescence clearly reflects the effect of heat on the photosynthetic systems in avocado fruit, its changes do not mirror the beneficial effects of pretreatment on fruit quality following HWT. The corollary to this is that the health of the photosynthetic apparatus does not necessarily reflect the overall health of avocado skin, and that the functionality of the photosynthetic apparatus may be irrelevant to the quality of avocados.

\section{Literature Cited}

Adams, W.W., B. Demmig-Adams, K. Winter, and U. Schreiber. 1990, The ratio of variable to maximum chlorophyll fluorescence from photo system II, measured in leaves at ambient temperature and at $77 \mathrm{~K}$, as an indicator of the photon yield of photosynthesis. Planta 180:166-174.

Amen, D.I. 1949. Copper enzymes in isolated chloroplasts, Polyphenyl oxidase in Beta vulgaris. Plant Physiol. 24: 1-15,

Berry, J. and O. Bjorkman. 1980. Photosynthetic response and adaptation to temperature in higher plants. Annu. Rev. Plant Physiol. 31:491-543.

Bjorkman, O. and B. Demmig. 1987. Photon yield of $\mathrm{O}_{2}$ evolution and chlorophyll fluorescence characteristics at $77 \mathrm{~K}$ among vascular plants of diverse origins, Planta 170:489-504.

Couey, H.M. and C.F. Hayes. 1986. Quarantine procedure for Hawaiian papaya using fruit selection and a two stage hot-water immersion. J. Econ. Entomol. 79:1307-1314.

Greer, D.H. and W.A. Laing. 1988. Photoinhibition of photosynthesis in intact kiwifruit (Actinidia deliciosa) leaves: Recovery and its dependence on temperature. Planta 174: 159-165.

Greer, D.H., W.A. Laing, and T. Kipnis. 1988. Photoinhibition of photosynthesis in intact kiwifruit (Actinidia deliciosa) leaves: Effect of temperature. Planta 174:152-158.

Gross, J. and I. Ohad. 1983. In Vivo fluorescence spectroscopy of chlorophyll in various unripe and ripe fruit. Photochem. Photobiol. 37:195-200.

Havaux, M. 1993a. Characterization of the heat damage to the photosynthetic electron transport system in potato leaves. Plant Science 94:19-33.

Havaux, M. 1993b. Rapid photosynthetic adaptation to heat stress triggered in potato leaves by moderately elevated temperatures. Plant, Cell and Environ, 16:461-467.

Havaux, M. and R. Lannoye. 1983. Chlorophyll fluorescence induction: A sensitive indicator of water stress in maize plants. Irr. Sci 4:147-151.

Havaux, M., H. Greppin, and R.J. Strasser. 1991, Functioning of photosystems I and II in pea leaves exposed to heat stress in the presence or absence of light. Planta 186:88-98.

Hopkirk, G., A. White, D.J. Beever, and S.K. Forbes. 1994. Influence of postharvest temperatures and the rate of fruit ripening on internal postharvest rots and disorders of New Zealand "Hass" avocado fruit. New Zealand J. Crop Hort. Sci. 22:305-311,

Janssen, L.H.J. and P.R. van Hasselt. 1994. Temperature effects on chlorophyll fluorescence induction in tomato. J. Plant Physiol. 144: 129-135.

Jessup, A.J. 1994. Quarantine disinfestation of 'Hass' avacados against Bactrocera tryoni (diptera: tephiritdae) with a hot fungicide dip followed by cold storage. J. Econ. Entomol. 87: 127-130.

Joyce, D.C. and A.J. Shorter. 1994. High-temperature conditioning reduces hot water treatment injury of 'Kensington Pride' mango fruit. HortScience 29: 10471051.

van Kooten, O. and J.F.H. Snel. 1990. The use of chlorophyll fluorescence nomenclature in plant stress physiology. Photosynthesis Res. 25:147-150.

Lafuente, M.T., A. Belver, M.G. Guye, and M.E. Saltveit. 1991, Effect of temperature conditioning on chilling injury of cucumber cotyledons. Plant Physiol. 95:443-449.

Paull, R.E. and N.J. Chen. 1990. Heat shock response in field-grown, ripening papaya fruit. J. Amer. Soc. Hort. Sci. 115:623-631.

Schreiber, U. and J.A. Berry, 1977. Heat-induced changes of chlorophyll fluorescence in intact leaves correlated with damage to the photosynthetic apparatus. Planta 136:233-238.

Schreiber, U., U. Schliwa, and W. Bilger. 1986. Continuous recording of photochemical and non-photochemical chlorophyll fluorescence quenching with a new type of modulation fluorimeter. Photosynthesis Res. 10:51-62.

Sharp, J.L. 1990. Immersion in heated water as a quarantine treatment for California stone fruits infested with the Caribbean fruit fly (Diptera: Tephritidae). J. Econ. Entomol. 83:1468-1479.

Smillie, R.M. 1992. Calvin cycle activity in fruit and the effect of heat stress. Scientia Hort. 51:83-95.

Thayer, S.S. and O. Bjorkman. 1990. Leaf xanthophyll content and composition in sun and shade determined by HPLC. Photosynthesis Res. 23:331-343.

Vamos-Vigyazo, L. 1981. Polyphenol oxidase and peroxidase in fruits and vegetables. CRC Critical Rev. Food Sci. Nutr. 6:49-127.

Woolf, A.B. and M. Lay-Yee. 1996. Effect of pretreatment on response of 'Hass' avocado to hot water disinfestation treatments. J. Amer. Soc. Hort. Sci. (In press.) 